UCRL-ID-119557

\title{
CHEMSODE: A Stiff ODE Solver for the Equations of Chemical Kinetics
}

\author{
Colin J. Aro \\ Lawrence Livermore National Laboratory \\ 7000 East Avenue, L-262 \\ Livermore, CA 94550 \\ and \\ Dept. of Applied Science \\ University of California, Davis \\ P.O. Box 808, L-794 \\ Livermore, CA 94550
}

January 1995

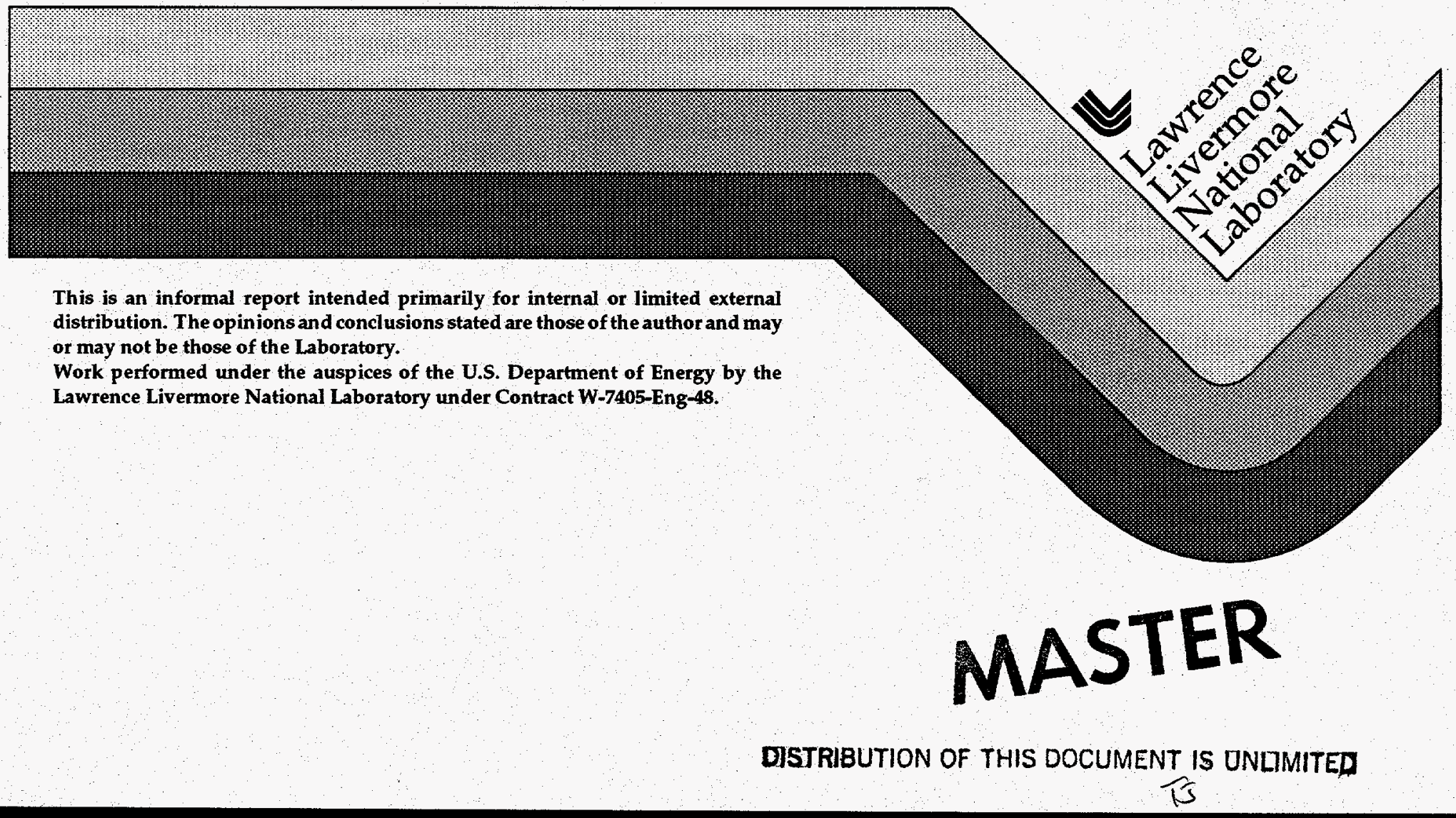




\section{DISCLAIMER}

This document was prepared as an acccount of work sponsored by an agency of the United States Government. Neither the United States Government nor the University of California nor any of their employees, makes any warranty, express or implied, or assumes any legal liability or responsibility for the accuracy, completeness, or usefulness of any information, apparatus, product, or process disclosed, or represents that its use would not infringe privately own rights. Reference herein to any specifie commercial products, process, or service by trade name, trademark, manufacturer, or otherwise, does not necessarily constitute or imply its endorsement, recommendation, or favoring by the United States Government or the University of California. The views and opinions of authors expressed herein do not necessarily state or reflect those of the United States Government or the University of California, and shall not be used for advertising or product endorsement purposes.

This report has been reproduced directly from the best available copy.

Available to DOE and DOE contractors from the Office of Scientific and Technical Information P.O. Box 62, Oak Ridge, IN 37831

Prices available from (615) 576-8401, FIS 626-8401

Available to the public from the National Technical Information Service

U.S. Department of Commerce 5285 Port Royal Rd., Springfield, VA 22161 


\section{DISCLAIMER}

Portions of this document may be illegible in electronic image products. Images are produced from the best available original document. 


\title{
CHEMSODE: A Stiff ODE Solver for the Equations of Chemical Kinetics
}

\author{
Colin J. Aro \\ Lawrence Livermore National Laboratory \\ and \\ Dept. of Applied Science, Univ. of Calif., Davis \\ P.O. Box 808, L-794, Livermore, California 94550
}

Subject Classifications:

65L05: Numerical Analysis-Initial Value Problems

76AA05: Chemically Reacting Flows

Keywords:

Atmospheric Chemistry, Preconditioning, Stiff ODEs 


\subsection{Introduction}

This report describes the CHEMSODE package: a collection of FORTRAN subroutines for the automatic integration of systems of ordinary differential equations arising in atmospheric chemical kinetics. These problems can be cast in the nonlinear form:

$$
\frac{d y}{d t}=R(y, t)=P(y, t)-\hat{L}(y, t) \dot{y}-\bar{L}(y, t) y^{2}
$$

where $y(t)$ is the vector of chemical concentrations, $y^{2}(t)$ is the vector containing the square of each chemical concentration, $P(y, t)$ is a vector representing the "production rate" term, while $\hat{L}(y, t)$ and $\bar{L}(y, t)$ are diagonal matrices representing the "loss rate" terms. Interesting to note are the forms that these production and loss rates take. We have $P_{i}=\sum_{q} k_{q} y_{u_{q}}^{j_{q}} y_{v_{q}}^{r_{q}} y_{w_{q}}^{s_{q}}$, where the components of the chemical concentration vector are raised to the powers $j_{q}, r_{q}, s_{q}$ which are either zero or one, depending on the chemical reactions in the problem. Further, $u_{q}, v_{q}, w_{q} \neq i$ for each $q$, so that $P_{i}$ does not depend on $y_{i}$. The $k_{q}$ represent reaction rates and may be time dependent (for photochemical reactions, which are diurnally varying). Finally, $\hat{L}_{i i}$ and $\bar{L}_{i i}$ which we henceforth denote as $\hat{L}_{i}$ and $\bar{L}_{i}$, have the forms $\hat{L}_{i}=\sum_{q} k_{q} y_{u_{q}}^{j_{q}} y_{v_{q}}^{r_{q}}$ and $\bar{L}_{i}=\sum_{q} k_{q} y_{u_{q}}^{j_{q}}$ where the exponents of the chemical concentrations are again either zero or one and none of the subscripts is equal to $i[1,4,5,6]$.

\subsection{Methods and Theory}

CHEMSODE uses a class of method derived from the family of implicit multistep methods called Preconditioned Time Difference methods [1]. These methods have the advantage that they are highly stable for stiff problems, while being explicitly computable and requiring no Jacobian matrix for the class of chemical kinetics equations (1). 
We illustrate the basic idea behind preconditioned time differencing by considering the first order nonlinear system of ordinary differential equations:

$$
\frac{d y}{d t}=f(y, t), \quad \mathrm{y}(0)=y_{0}
$$

A $\mathbf{k}$ step implicit multistep formula for solving these equations is

$$
y^{n+1}=\Delta t \beta_{k} f\left(y^{n+1}, t_{n+1}\right)+g^{n}
$$

(with $\Delta t=$ stepsize, $t_{n+1}=(n+1) \Delta t, y^{n+1} \cong y\left(t_{n+1}\right), \beta_{k}=$ const., and $g^{n}$ a known vector).

Fixed point iteration for the solution of the nonlinear system in Eq. (3) begins by defining the function

$$
G(y)=\Delta t \beta_{k} \mathrm{f}\left(y, t_{n+1}\right)+g^{n}
$$

and then performing the iteration

$$
\left(y^{n+1}\right)^{(m+1)}=G\left(\left(y^{n+1}\right)^{(m)}\right),\left(y^{n+1}\right)^{(0)}=\text { arbitrary. }
$$

Convergence of the iteration to $y^{n+1}$ will occur if the initial guess $\left(y^{n+1}\right)^{(0)}$ is chosen in a neighborhood of contraction of $G$ about $y^{n+1}$, [1]. If $G$ is not contractive at $y^{n+1}$ then the fixed point iteration may diverge.

The problem of diverging or slowly converging fixed point iteration schemes can often be rectified by "preconditioning". That is, a function $F(v, u, t)$ is defined such that $F(v, v, t)=G(v, t)$; the iterates are then computed in the following fashion:

$$
\left(y^{n+1}\right)^{(m+1)}=F\left(\left(y^{n+1}\right)^{(m+1)},\left(y^{n+1}\right)^{(m)}, t_{n+1}\right),\left(y^{n+1}\right)^{(0)}=\text { arbitrary. }
$$

If this procedure were to converge, say to $y^{n+1}$, then we see that 


$$
y^{n+1}=F\left(y^{n+1}, y^{n+1}, t_{n+1}\right)=G\left(y^{n+1}, t_{n+1}\right)=\Delta t \beta_{k} f\left(y^{n+1}, t_{n+1}\right)+g^{n}
$$

and the desired solution is obtained. Although each iteration requires the solution of another non-linear system of equations, this may not be difficult if the preconditioner $F$ is defined appropriately. In this report, we consider the Jacobi preconditioner

$F_{i}(u, v, t)=\Delta t \quad \beta_{k} f_{i}\left(v_{1}, v_{2}, \ldots, v_{i-1}, u_{i}, v_{i+1}, \ldots, v_{N}, t\right)+g_{i}{ }^{n},[1]$.

Now, if the iteration is terminated prematurely after, say, $l$ iterations and we set $y^{n+1}=\left(y^{n+1}\right)^{(l)}$, then we generate time differencing methods of the form:

1. Set $\left(y^{n+1}\right)^{0}$ (the initial guess).

2. For $v=1,2, \ldots, l$, compute $\left(y^{n+1}\right)^{(v)}=F\left(\left(y^{n+1}\right)^{(v)},\left(y^{n+1}\right)^{(v-1)}, t_{n+1}\right)$

3. Set $y^{n+1}=\left(y^{n+1}\right)^{(l)}$

These are the so-called Preconditioned Time Differencing methods.

\subsection{A First Order Method}

To illustrate, consider the application of the Jacobi preconditioner to the backward Euler method and use $\left(y^{n+1}\right)^{0}=y^{n}$ (known as the identity predictor) as the initial guess. Taking only a single iteration $(l=1)$, we then have:

$$
y_{i}^{n+1}=\Delta t f_{i}\left(y_{1}^{n}, \ldots, y^{n}{ }_{i-1}, y_{i}{ }^{n+1}, y^{n}{ }_{i+1}, \ldots, t\right)+y^{n}{ }_{i} .
$$

Additional iterations would yield:

$$
\left(y_{i}^{n+1}\right)^{\vee}=\Delta t f_{i}\left(\left(y_{1}^{n+1}\right)^{\mathrm{v}-1}, \ldots,\left(y_{i}^{n+1}\right)^{\mathrm{v}-1},\left(y_{i}^{n+1}\right)^{\mathrm{v}},\left(y_{i}^{n+1}\right)^{\mathrm{v}-1}, \ldots, t\right)+y_{i}^{n}
$$

which, when applied to Eq. (1) give us:

$$
\left(y_{i}^{n+1}\right)^{v}=y_{i}^{n}+\Delta t\left(\left(P_{i}^{n+1}\right)^{v-1}-\left(\hat{L}_{i}^{n+1}\right)^{v-1}\left(y_{i}^{n+1}\right)^{v}-\left(\bar{L}_{i}^{n+1}\right)^{\mathrm{v}-1}\left(\left(y_{i}^{n+1}\right)^{v}\right)^{2}\right)(7)
$$


We see that we must solve a quadratic equation to obtain $\left(y_{i}^{n+1}\right)^{v}$. The two roots of this equation are a positive and a negative real number and we set $\left(y_{i}^{n+1}\right)^{v}$ to be the positive root. Even with a single iteration, this method retains the first order accuracy of the backward Euler method, and seems to be unconditionally stable for the class of chemical kinetics problems [1]. Note that it is explicitly computable.

\subsection{A Second Order Method}

The implementation of a second order technique proceeds along similar lines: We start with the trapezoidal rule, and apply the Jacobi preconditioner. In this case, however, we must use at least a first order predicted value for $\left(y^{n+1}\right)^{0}$ to retain the method's second order accuracy [1]. In this report, we use the first order Jacobi preconditioned method (7) to obtain this predicted value, because of its superior stability.

The algorithm and component equations for a single iteration of this method, taken from [1], are:

1. Set $\left(y^{n+1}\right)^{0}=\hat{y}^{n+1}$, the computed value from the Jacobi preconditioned Backward Euler method.

2. Calculate $P^{n+1}, \hat{L}^{n+1}, \bar{L}^{n+1}$ using these values

3. Solve

$$
y_{i}^{n+1}=\frac{\Delta t}{2}\left[\left(P_{i}^{n+1}-\hat{L}_{i}^{n+1} y_{i}^{n+1}-\bar{L}_{i}^{n+1}\left(y_{i}^{n+1}\right)^{2}\right)+\left(P_{i}^{n}-\hat{L}_{i}^{n} y_{i}^{n}-\bar{L}_{i}^{n}\left(y_{i}^{n}\right)^{2}\right)\right]+y_{i}^{n}
$$

for $y_{i}^{n+1}$ using the positive root. Multiple iterations, as in (7) are implemented in the obvious way.

Error control is a significant challenge for these methods. The choices are extreme with little possibility for an "in between" compromise. In [1], we used a method of comparing the 
calculation of two half steps with a single whole step. This was fairly accurate but obviously expensive. The alternative is an inaccurate estimate of a quantity that "looks like" our truncation error where we hope to err on the conservative side. We thus use the local error indicator:

$$
E^{n+1}=\frac{2}{c+1}\left(c y^{n+1}-(1+c) y^{n}+y^{n-1}\right)
$$

with $c=\frac{\left(t_{n}-t_{n-1}\right)}{\left(t_{n+1}-t_{n}\right)}$. This indicator gives us an estimate of $\Delta t^{2} y^{\prime \prime}\left(t_{n}\right)+O\left(\Delta t^{3}\right)$, which is a bit conservative, but was used with success in [5]. Given the values ATOL(I) and RTOL(I), the componentwise absolute and relative tolerances, we compute the value

$$
\max _{i}\left(\frac{E_{i}^{n+1}}{\operatorname{ATOL}(I)+\operatorname{RTOL}(I) y_{i}^{n}}\right) \equiv\left\|E^{n+1}\right\|
$$

If this value is less than one, the step is accepted. The new stepsize is computed using the formula

$$
\Delta t_{\text {new }}=\left(\frac{0.94}{\sqrt{\left\|E^{n+1}\right\|}}\right) \Delta t_{\text {old }}
$$

subject to prescribed minimum and maximum values (to be described later) and a maximum ratio increase.

CHEMSODE is written in the same spirit as the more general LSODE package [3], used for the automatic integration of the general first order ODE system.

\subsection{Code}

At this time, CHEMSODE uses a second order method (the trapezoidal rule) with a Jacobi preconditioner (one iteration). The package consists of the following subroutines:

\subsubsection{SOLVER}

SOLVER is the driver for the package. It takes the following arguments: 
- F: (EXT) Name of the subroutine for the right hand side of the ODE system (the derivative). This is supplied by the user and must be declared as EXTERNAL in the calling program, having the form

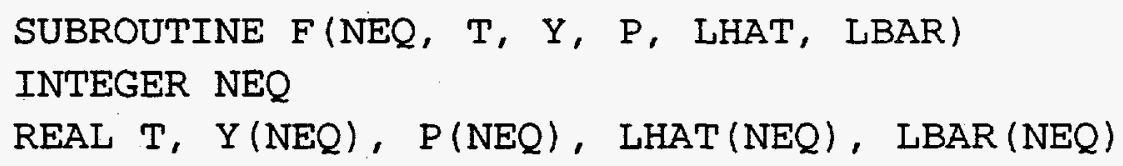

The inputs are NEQ, $T$ and $Y$ (the number of ODEs, current time and chemical species concentrations). $\mathrm{F}$ is to set the chemical production and loss terms P(i), LHAT(i), LBAR(i).

- NEQ: (IN) The number of first order ODEs.

- Y: (INOUT) Array of components of the $Y(t)$ (dependent variable) from Eq. (1). $Y$ shall be dimensioned at least NEQ elements long. On initial call, it contains the species concentrations at $\mathrm{t}=\mathrm{T}$. On return, it contains the values at $\mathrm{t}=$ TOUT (see below).

- T: (INOUT) Value of the independent variable. Upon return, it will contain the value TOUT.

- TOUT: (IN) The next point where output is desired.

- ATOL: (IN) Array of absolute error tolerances (size NEQ).

- RTOL: (IN) Array of relative error tolerances (size NEQ).

- RWORK: (WORK) This work array must be dimensioned at least $10 *$ NEQ real elements long. It is also used to pass optional arguments to the solver (see below IOPT).

- IOPT: (IN) Indicates whether the user has supplied optional input. IOPT $=0$ indicates no optional input. IOPT $=1$ indicates that RWORK(1) contains the first stepsize to be attempted, RWORK(2) contains the maximum allowable stepsize, and RWORK(3) contains the minimum allowable stepsize. Default values recently used are RUMACH (see below), 1 second, and 1 hour respectively. A non-zero minimum is required since our "loose" method of step control has problems otherwise.

- ITASK: (IN) Indicates whether the call is a continue or a restart. ITASK $=0$ indicates a restart. ITASK = 1 indicates a continue. 
A flowchart for SOLVER is provided in Figure 2, and is very run-of-the-mill for this type of code. At this stage there is very little error checking and recovery, however the code has proven to be quite bullet-proof in our experiences. In adjusting the new stepsize, if two successive steps are rejected, the stepsize is automatically reduced to the minimum allowable; that is, the method is restarted.

\subsubsection{STEP2}

STEP2 takes a single discrete time step and returns an estimate of the error to the SOLVER routine. The stepsize attempted is specified by the SOLVER routine. The error estimate is based on the formula of Eq (9). This information is passed back to the SOLVER routine which calculates the quantities in Eqs. (10) and (11) and accepts or rejects the step accordingly (while adjusting the stepsize for the next try).

\subsubsection{ADVANCE2}

ADVANCE2 implements the component equations for the preconditioned trapezoidal rule assuming that the production and loss rates are set. It essentially provides for the solution

of Eq (8) for $y_{i}^{n+1}$ assuming all other values are explicitly known (which they are). It uses a scalar newton iteration and a fixed number of iterations (two). This works well with a close enough initial guess $\left(y_{i}^{n}-\right.$ not to be confused with the initial guess for the preconditioner). Attempts at using the quadratic formula proved unsuccessful since it requires the subtraction of two positive quantities that are nearly equal.

\subsubsection{ADVANCE1}

ADVANCE1 implements the component equations for the preconditioned backward Euler method, again assuming that the production and loss rates are set. This is Eq (7) and is done in a manner identical with that in ADVANCE2.

\subsubsection{RUMACH}

RUMACH calculates the machine's unit roundoff in a machine independent manner. 
FIGURE 1. CHEMSODE subroutine calling hierarchy.

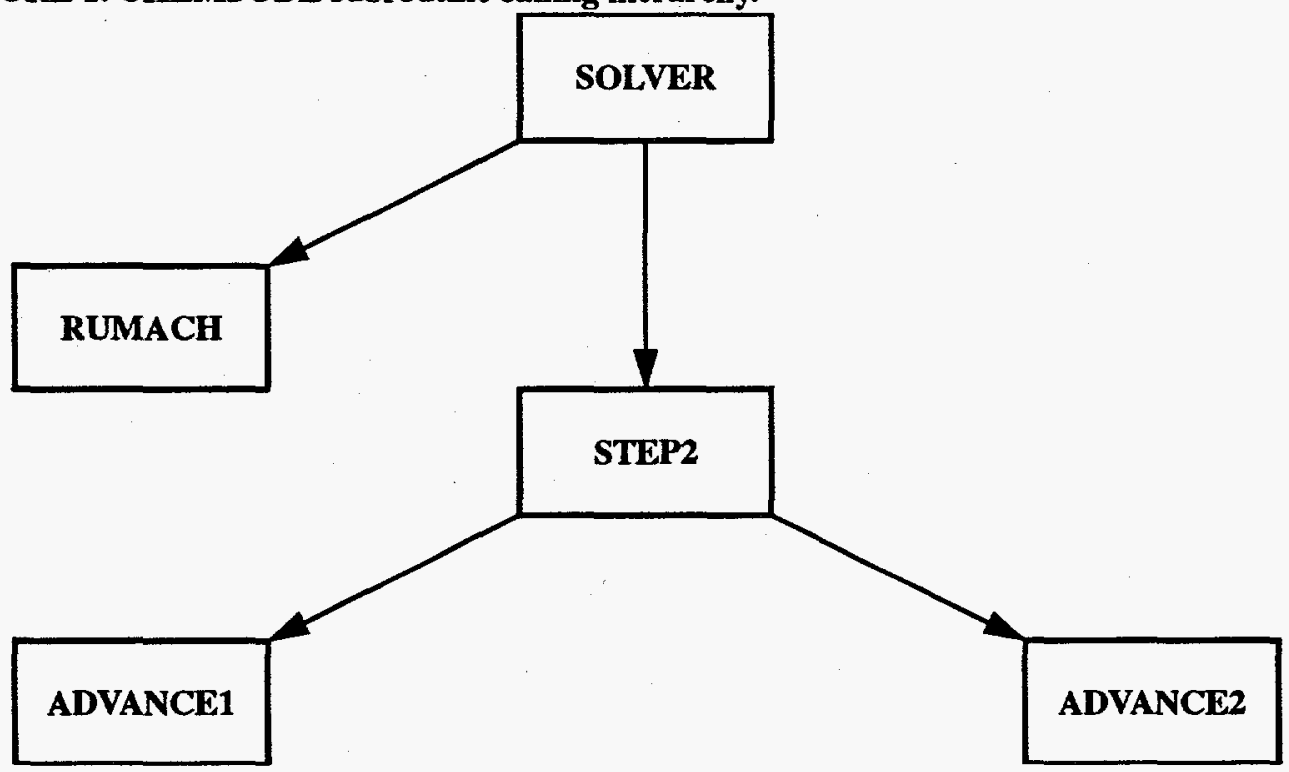


FIGURE 2. Flowchart for the CHEMSODE algorithm. (Subroutine SOLVER)

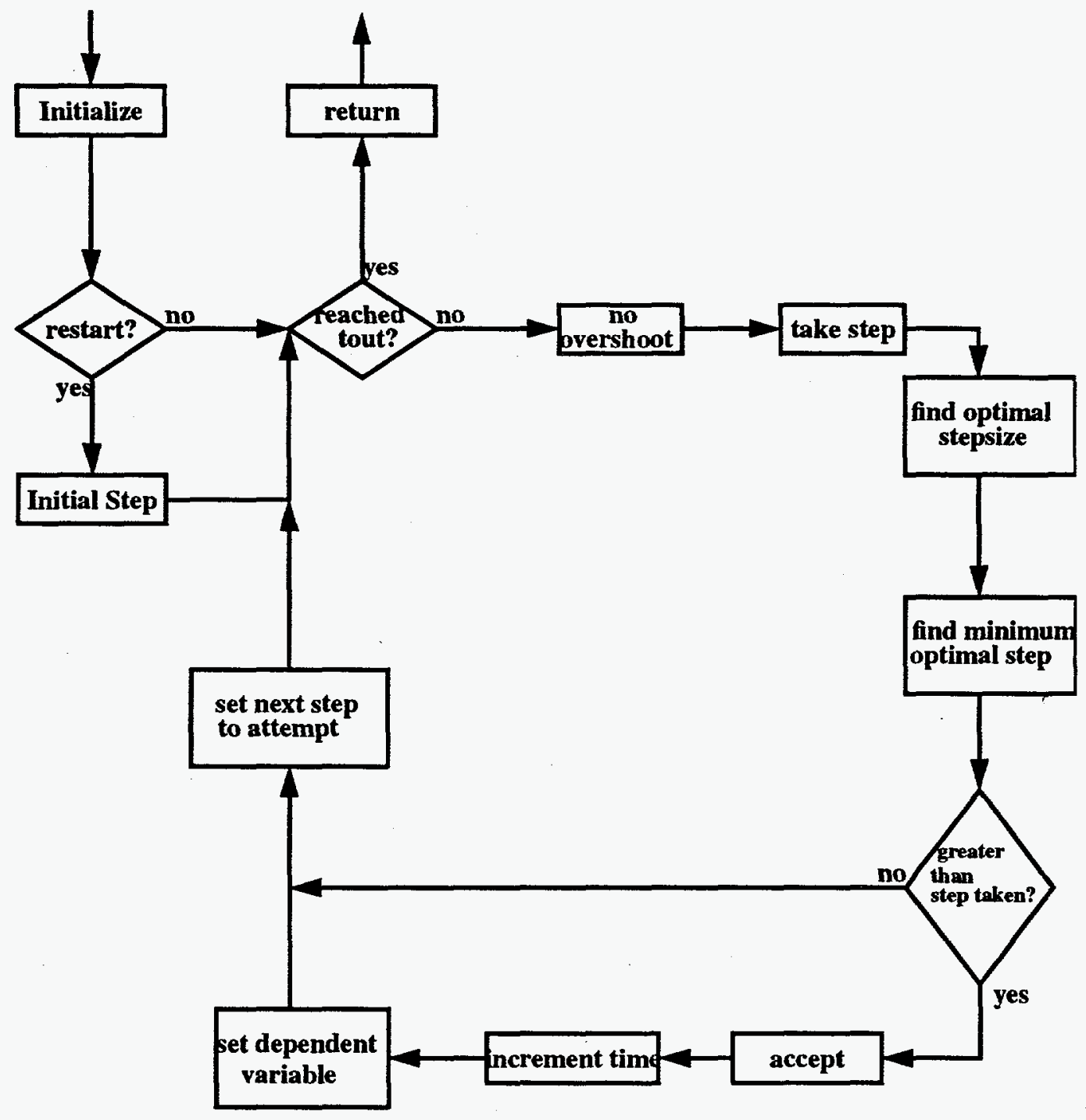




\subsection{Code usage and Example Problem}

The reader will find strong similarities between LSODE's calling sequence (and parameters) and CHEMSODE's. CHEMSODE's parameters shall be declared as follows:

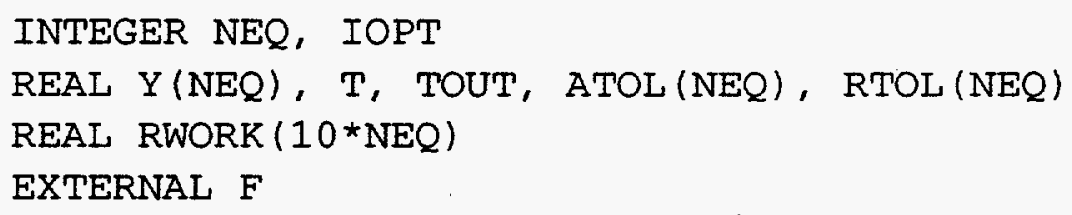

The solver is then called in the main program

CALL SOLVER (NEQ, F, Y, T, TOUT, ATOL, RTOL, 1 RWORK, IOPT, ITASK)

\subsection{EXAMPLE}

We use a simple problem from chemical kinetics. The Chapman atmosphere has been dealt with previously $[1,2]$. It can be written in a simplified form Eq. (1) for $y=\left[\begin{array}{l}y_{1} \\ y_{2}\end{array}\right]$, with

$$
\begin{gathered}
P(y, t)=\left[\begin{array}{c}
2 k_{3}(t) y_{3}+k_{4}(t) y_{2} \\
k_{1} y_{1} y_{3}
\end{array}\right] \\
\hat{L}(y, t)=\left[\begin{array}{cc}
k_{1} y_{3}+k_{2} y_{2} & 0 \\
0 & k_{2} y_{1}+k_{4}(t)
\end{array}\right] \\
(\bar{L}=0)
\end{gathered}
$$

and the constant values

$$
\begin{aligned}
& y_{3}=3.7 \times 10^{16} \\
& k_{1}=1.63 \times 10^{-16} \\
& k_{2}=4.66 \times 10^{-16}
\end{aligned}
$$


and

$$
k_{i}=\left\{\begin{array}{c}
\exp \left[\frac{-a_{i}}{\sin \omega t}\right], \sin \omega t>0 \\
0, \sin \omega t \leq 0
\end{array}, i=3,4\right.
$$

with

$$
a_{3}=22.62, a_{4}=7.601, \omega=\frac{\pi}{43200}
$$

The constant 43200 is just twelve hours in seconds, so that the diurnally varying rates $\left(k_{3}\right.$ and $k_{4}$ ) have 24 hour periods. Initial conditions are $y_{1}(0)=10^{6}, y_{2}(0)=10^{12}$. The Chapman mechanism has important characteristics shared by the larger problems in atmospheric chemistry in that:

- The Jacobian of the differential system is non-constant.

- The diurnal effect is present.

- The oscillations are fast (in comparison to the scale of integration),

cf. $[1,2]$. This problem can be coded:

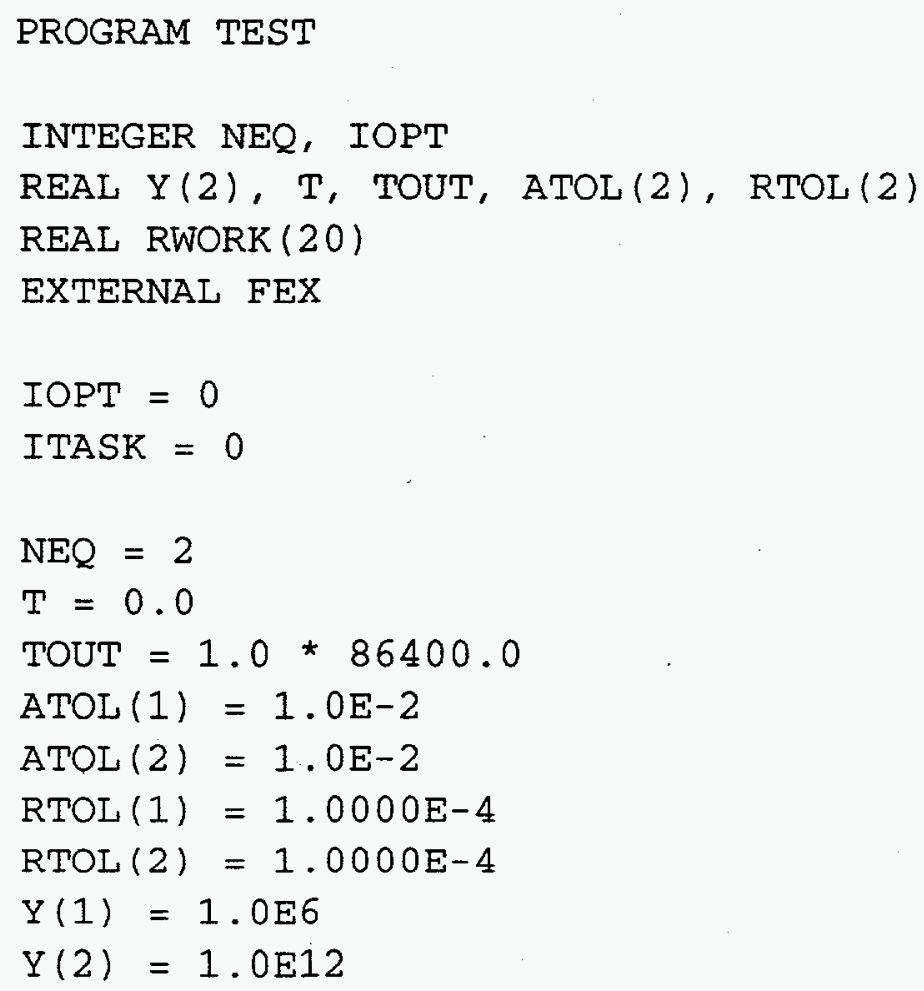


CALL SOLVER (NEQ, FEX, Y, T, TOUT, ATOL, RTOL, 1RWORK, IOPT, ITASK)

PRINT *, 'VALUES AT TIME ', T, 'ARE ', Y

END

SUBROUTINE FEX(NEQ, T, Y, P, LHAT, LBAR)

INTEGER NEQ

REAL $T, Y(*), P(*), \operatorname{LHAT}(*), \operatorname{LBAR}(*)$

REAL K1，K2，Y3

REAL K3， K4

REAL $K$

PARAMETER $(\mathrm{K} 1=1.63 \mathrm{E}-16)$

PARAMETER $(K 2=4.66 \mathrm{E}-16)$

PARAMETER ( $Y 3=3.7 E 16)$

$\mathrm{P}(1)=2.0 * \mathrm{~K} 3(\mathrm{~T}) * \mathrm{Y} 3+\mathrm{K} 4(\mathrm{~T}) * \mathrm{Y}(2)$

$P(2)=K 1 * Y(1) \star Y 3$

$\operatorname{LHAT}(1)=\mathrm{K} 1 * \mathrm{Y} 3+\mathrm{K} 2 * \mathrm{Y}(2)$

$\operatorname{LHAT}(2)=\mathrm{K} 2 * \mathrm{Y}(1)+\mathrm{K} 4(\mathrm{~T})$

$\operatorname{LBAR}(1)=0.0$

$\operatorname{LBAR}(2)=0.0$

RETURN

END

REAL FUNCTION K3 (T)

REAL T

REAL PI, OMEGA, A3

PARAMETER ( $P I=3.14159265358979323846264338)$ 
PARAMETER (OMEGA $=\mathrm{PI} / 43200.0)$

PARAMETER (A3 $=22.62)$

REAL TEMP

$T E M P=S I N(T * O M E G A)$

IF (TEMP .GT. 0.0$)$ THEN

$\mathrm{K} 3=\operatorname{EXP}(-\mathrm{A} 3 / \mathrm{TEMP})$

ELSE

$\mathrm{K} 3=0.0$

END IF

RETURN

END

REAL FUNCTION K4 (T)

REAL T

REAL PI, OMEGA, A4

PARAMETER ( $P I=3.14159265358979323846264338)$

PARAMETER (OMEGA $=\mathrm{PI} / 43200.0)$

PARAMETER (A4 = 7.601)

REAL TEMP

TEMP $=\operatorname{SIN}(T *$ OMEGA $)$

IF (TEMP .GT. 0.0 ) THEN

$\mathrm{K} 4=\operatorname{EXP}(-\mathrm{A} 4 / \mathrm{TEMP})$

ELSE

$\mathrm{K} 4=0.0$

END IF

RETURN

END 


\subsection{References}

1. C. J. Aro and G. H. Rodrigue, "Preconditioned Time Differencing for Stiff ODEs in Diurnal Atmospheric Kinetics", Report UCRL-JC-118092, LLNL, Livermore, CA, 1994 (unpublished)

2. G. D. Byrne and A. C. Hindmarsh, "Stiff ODE Solvers: A Review of Current and Coming Attractions", Journal of Computational Physics, Vol. 70, No. 1, Academic Press, Inc., 1987, pp. 1-62

3. K. Radhakrishnan and A. C. Hindmarsh, "Description and Use of LSODE, the Livermore Solver for Ordinary Differential Equations", Report UCRL-ID-113855, LLNL, Livermore, CA, 1993

4. J.I. Steinfeld, J.S. Francisco, and W.L. Hase, Chemical Kinetics and Dynamics, Prentice Hall, Englewood Cliffs, New Jersey (1989)

5. J. G. Verwer. "Gauss-Seidel Iteration for Stiff ODEs from Chemical Kinetics". Report NM-R9315, CWI, Amsterdam, 1993 (in press SIAM J. Sci. Comput.)

6. J.G. Verwer, M. van Loon, “An Evaluation of Explicit Pseudo-Steady State Approximation Schemes for Stiff ODE Systems from Chemical Kinetics". CWI Report NMR9312, Centre for Mathematics and Computer Science, Amsterdam, 1993 (in press $J$. Comput. Phys.)

7. D. J. Wuebbles, J. S. Tamaresis, and K. O. Patten, "Quantified Estimates of Total, GWPs for Greenhouse Gases Taking into Account Tropospheric Chemistry", Report UCRL-ID-115850, LLNL, Livermore, CA, 1993. (unpublished)

\subsection{Appendix: The Box Model}

CHEMSODE is currently being applied to a set of chemical kinetic equations taken from the LLNL two dimensional chemical-radiative-transport model of the earth's atmosphere [7]. The "Box Model" has been developed to isolate these equations from the other unrelated processes taking place in the full models (e.g. advection, diffusion). It uses the same 
chemistry and associated radiative transfer calculations as the full model. The attempt is to isolate a single zone from the full model in order to more accurately test the merits of various chemical kinetics solvers.

Initial tests are being run with a set of twenty chemical species listed in the following tables. Photolytic and thermal reactions, along with the two species assumed to be in equilibrium are also given.

TABLE I. Chemically reactive species used in the box model.

\begin{tabular}{llllll}
\hline $\mathrm{O}_{3}$ & $\mathrm{~N}_{2} \mathrm{O}$ & $\mathrm{NO}$ & $\mathrm{NO}_{2}$ & $\mathrm{NO}_{3}$ & $\mathrm{~N}_{2} \mathrm{O}_{5}$ \\
$\mathrm{HONO}$ & $\mathrm{HNO}_{3}$ & $\mathrm{HO}_{2} \mathrm{NO}_{2}$ & $\mathrm{H}_{2} \mathrm{O}$ & $\mathrm{OH}$ & $\mathrm{HO}_{2}$ \\
$\mathrm{H}_{2} \mathrm{O}_{2}$ & $\mathrm{H}_{2}$ & $\mathrm{CH}_{4}$ & $\mathrm{CH}_{3} \mathrm{O}_{2}$ & $\mathrm{CH}_{3} \mathrm{OOH}$ & $\mathrm{CH}_{2} \mathrm{O}$ \\
$\mathrm{CO}$ & $\mathrm{CH}_{3} \mathrm{O}_{2} \mathrm{NO}_{2}$ & & & &
\end{tabular}

TABLE II. Chemical species assumed to be in steady state for the box model. $O\left({ }^{\mathrm{T} D}\right) O$

TABLE III. Thermal reactions in the Box Model

\begin{tabular}{ll}
\hline$O+O_{2}$ & $\rightarrow O_{3}$ \\
$O+O_{3}$ & $\rightarrow 2 O_{2}$ \\
$O\left({ }^{1} D\right)+N_{2}$ & $\rightarrow O+N_{2}$ \\
$O\left({ }^{1} D\right)+O_{2}$ & $\rightarrow O+O_{2}$ \\
$O\left({ }^{1} D\right)+O_{3}$ & $\rightarrow 2 O_{2}$ \\
$O\left({ }^{1} D\right)+O_{3}$ & $\rightarrow \mathrm{O}_{2}+2 \mathrm{O}$ \\
$\mathrm{H}_{2} O+O\left({ }^{1} D\right)$ & $\rightarrow 2 O H$ \\
$O\left({ }^{1} D\right)+\mathrm{H}_{2}$ & $\rightarrow O H+\mathrm{HO}_{2}$ \\
$\mathrm{~N}_{2} \mathrm{O}+O\left({ }^{1} \mathrm{D}\right)$ & $\rightarrow \mathrm{N}_{2}+\mathrm{O}_{2}$ \\
$\mathrm{~N}_{2} \mathrm{O}+\mathrm{O}\left({ }^{1} \mathrm{D}\right)$ & $\rightarrow 2 \mathrm{NO}$
\end{tabular}


TABLE III. Thermal reactions in the Box Model

\begin{tabular}{|c|c|c|}
\hline $\mathrm{CH}_{4}+\mathrm{O}\left({ }^{1} \mathrm{D}\right)$ & $\rightarrow$ & $\mathrm{CH}_{2} \mathrm{O}+\mathrm{H}_{2}$ \\
\hline $\mathrm{CH}_{4}+\mathrm{O}\left({ }^{1} \mathrm{D}\right)$ & $\rightarrow$ & $\mathrm{CH}_{3} \mathrm{O}_{2}+\mathrm{OH}$ \\
\hline $\mathrm{H}_{2}+\mathrm{OH}$ & $\rightarrow$ & $\mathrm{H}_{2} \mathrm{O}+\mathrm{HO}_{2}$ \\
\hline $\mathrm{OH}+\mathrm{O}_{3}$ & $\rightarrow$ & $\mathrm{HO}_{2}+\mathrm{O}_{2}$ \\
\hline$O H+O$ & $\rightarrow$ & $\mathrm{O}_{2}+\mathrm{HO}_{2}$ \\
\hline $\mathrm{HO}_{2}+\mathrm{O}$ & $\rightarrow$ & $\mathrm{OH}+\mathrm{O}_{2}$ \\
\hline $\mathrm{HO}_{2}+\mathrm{O}_{3}$ & $\rightarrow$ & $\mathrm{OH}+2 \mathrm{O}_{2}$ \\
\hline $\mathrm{HO}_{2}+\mathrm{OH}$ & $\rightarrow$ & $\mathrm{H}_{2} \mathrm{O}+\mathrm{O}_{2}$ \\
\hline $\mathrm{HO}_{2}+\mathrm{HO}_{2}$ & $\rightarrow$ & $\mathrm{H}_{2} \mathrm{O}_{2}+\mathrm{O}_{2}$ \\
\hline $2 \mathrm{HO}_{2}+\mathrm{H}_{2} \mathrm{O}$ & $\rightarrow$ & $\mathrm{H}_{2} \mathrm{O}_{2}+\mathrm{O}_{2}+\mathrm{H}_{2} \mathrm{O}$ \\
\hline $\mathrm{H}_{2} \mathrm{O}_{2}+\mathrm{OH}$ & $\rightarrow$ & $\mathrm{H}_{2} \mathrm{O}+\mathrm{HO}_{2}$ \\
\hline $\mathrm{NO}+\mathrm{O}_{3}$ & $\rightarrow$ & $\mathrm{NO}_{2}+\mathrm{O}_{2}$ \\
\hline $\mathrm{NO}+\mathrm{OH}$ & $\rightarrow$ & HONO \\
\hline $\mathrm{NO}+\mathrm{HO}_{2}$ & $\rightarrow$ & $\mathrm{NO}_{2}+\mathrm{OH}$ \\
\hline $\mathrm{NO}_{2}+\mathrm{O}$ & $\rightarrow$ & $\mathrm{NO}+\mathrm{O}_{2}$ \\
\hline $\mathrm{NO}_{2}+\mathrm{O}_{3}$ & $\rightarrow$ & $\mathrm{NO}_{3}+\mathrm{O}_{2}$ \\
\hline $\mathrm{NO}_{2}+\mathrm{HO}_{2}$ & $\rightarrow$ & $\mathrm{HO}_{2} \mathrm{NO}_{2}$ \\
\hline $\mathrm{NO}_{3}+\mathrm{NO}_{2}$ & $\rightarrow$ & $\mathrm{N}_{2} \mathrm{O}_{5}$ \\
\hline $\mathrm{N}_{2} \mathrm{O}_{5}$ & $\rightarrow$ & $\mathrm{NO}_{3}+\mathrm{NO}_{2}$ \\
\hline $\mathrm{NO}_{2}+\mathrm{OH}$ & $\rightarrow$ & $\mathrm{HNO}_{3}$ \\
\hline$H O N O+O H$ & $\rightarrow$ & $\mathrm{H}_{2} \mathrm{O}+\mathrm{NO}_{2}$ \\
\hline $\mathrm{HNO}_{3}+\mathrm{OH}$ & $\rightarrow$ & $\mathrm{H}_{2} \mathrm{O}+\mathrm{NO}+\mathrm{O}_{2}$ \\
\hline $\mathrm{HNO}_{3}+\mathrm{OH}$ & $\rightarrow$ & $\mathrm{H}_{2} \mathrm{O}+\mathrm{NO}_{2}+\mathrm{O}$ \\
\hline $\mathrm{HO}_{2} \mathrm{NO}_{2}$ & $\rightarrow$ & $\mathrm{HO}_{2}+\mathrm{NO}_{2}$ \\
\hline $\mathrm{HO}_{2} \mathrm{NO}_{2}+\mathrm{OH}$ & $\rightarrow$ & $\mathrm{H}_{2} \mathrm{O}+\mathrm{NO}_{2}+\mathrm{O}_{2}$ \\
\hline $\mathrm{CO}+\mathrm{OH}$ & $\rightarrow$ & $\mathrm{HO}_{2}$ \\
\hline $\mathrm{CH}_{4}+\mathrm{OH}$ & $\rightarrow$ & $\mathrm{CH}_{3} \mathrm{O}_{2}+\mathrm{H}_{2} \mathrm{O}$ \\
\hline $\mathrm{CH}_{2} \mathrm{O}+\mathrm{OH}$ & $\rightarrow$ & $\mathrm{H}_{2} \mathrm{O}+\mathrm{HO}_{2}+\mathrm{CO}$ \\
\hline $\mathrm{CH}_{3} \mathrm{O}_{2}+\mathrm{O}$ & $\rightarrow$ & $\mathrm{CH}_{2} \mathrm{O}+\mathrm{HO}_{2}$ \\
\hline
\end{tabular}


TABLE III. Thermal reactions in the Box Model

\begin{tabular}{lll}
\hline $\mathrm{CH}_{2} \mathrm{O}+\mathrm{O}$ & $\rightarrow \mathrm{HO}_{2}+\mathrm{OH}+\mathrm{CO}$ \\
$\mathrm{CH}_{3} \mathrm{O}_{2}+\mathrm{HO}_{2}$ & $\rightarrow \mathrm{CH}_{3} \mathrm{OOH}+\mathrm{O}_{2}$ \\
$\mathrm{CH}_{3} \mathrm{O}_{2}+\mathrm{CH}_{3} \mathrm{O}_{2}$ & $\rightarrow 2 \mathrm{CH}_{2} \mathrm{O}+1.4 \mathrm{HO}_{2}$ \\
$\mathrm{CH}_{3} \mathrm{O}_{2}+\mathrm{NO}$ & $\rightarrow \mathrm{HO}_{2}+\mathrm{CH}_{2} \mathrm{O}+\mathrm{NO}_{2}$ \\
$\mathrm{CH}_{3} \mathrm{O}_{2}+\mathrm{NO}_{2}$ & $\rightarrow \mathrm{CH}_{3} \mathrm{O}_{2} \mathrm{NO}_{2}$ \\
$\mathrm{CH}_{3} \mathrm{O}_{2} \mathrm{NO}_{2}$ & $\rightarrow \mathrm{CH}_{3} \mathrm{O}_{2}+\mathrm{NO}_{2}$ \\
$\mathrm{CH}_{3} \mathrm{OOH}+\mathrm{OH}$ & $\rightarrow \mathrm{CH}_{2} \mathrm{O}+\mathrm{H}_{2} \mathrm{O}+\mathrm{OH}$ \\
$\mathrm{CH}_{3} \mathrm{OOH}+\mathrm{OH}$ & $\rightarrow \mathrm{CH}_{3} \mathrm{O}_{2}+\mathrm{H}_{2} \mathrm{O}$
\end{tabular}

TABLE IV. Photolytic Reactions in the Box Model

\begin{tabular}{|c|c|c|}
\hline$O_{2}+h v$ & $\rightarrow$ & 20 \\
\hline$O_{3}+h v$ & $\rightarrow$ & $O+O_{2}$ \\
\hline$O_{3}+h v$ & $\rightarrow$ & $O\left({ }^{1} D\right)+O_{2}$ \\
\hline $\mathrm{H}_{2} \mathrm{O}_{2}+h v$ & $\rightarrow$ & $2 O H$ \\
\hline $\mathrm{NO}_{2}+h v$ & $\rightarrow$ & $\mathrm{NO}+\mathrm{O}$ \\
\hline $\mathrm{N}_{2} \mathrm{O}+h v$ & $\rightarrow$ & $N_{2}+O\left({ }^{1} D\right)$ \\
\hline $\mathrm{NO}_{3}+h v$ & $\rightarrow$ & $\mathrm{NO}_{2}+\mathrm{O}$ \\
\hline $\mathrm{NO}_{3}+h v$ & $\rightarrow$ & $\mathrm{NO}+\mathrm{O}_{2}$ \\
\hline $\mathrm{N}_{2} \mathrm{O}_{5}+h v$ & $\rightarrow$ & $\mathrm{NO}_{2}+\mathrm{NO}+\mathrm{O}_{2}$ \\
\hline $\mathrm{N}_{2} \mathrm{O}_{5}+h v$ & $\rightarrow$ & $2 \mathrm{NO}_{2}+\mathrm{O}$ \\
\hline $\mathrm{N}_{2} \mathrm{O}_{5}+h v$ & $\rightarrow$ & $\mathrm{NO}_{2}+\mathrm{NO}+2 \mathrm{O}$ \\
\hline $\mathrm{N}_{2} \mathrm{O}_{5}+h v$ & $\rightarrow$ & $2 \mathrm{NO}+\mathrm{O}_{2}+\mathrm{O}$ \\
\hline HONO + hv & $\rightarrow$ & $O H+N O$ \\
\hline $\mathrm{HNO}_{3}+h \mathrm{v}$ & $\rightarrow$ & $\mathrm{OH}+\mathrm{NO}_{2}$ \\
\hline $\mathrm{HO}_{2} \mathrm{NO}_{2}+h v$ & $\rightarrow$ & $\mathrm{OH}+\mathrm{NO}+\mathrm{O}_{2}$ \\
\hline $\mathrm{HO}_{2} \mathrm{NO}_{2}+h v$ & $\rightarrow$ & $\mathrm{OH}+\mathrm{NO}_{2}+\mathrm{O}$ \\
\hline $\mathrm{HO}_{2} \mathrm{NO}_{2}+h v$ & $\rightarrow$ & $\mathrm{HO}_{2}+\mathrm{NO}_{2}$ \\
\hline $\mathrm{CH}_{2} \mathrm{O}+h v$ & $\rightarrow$ & $\mathrm{CO}+\mathrm{H}_{2}$ \\
\hline $\mathrm{CH}_{2} \mathrm{O}+h \mathrm{~V}$ & $\rightarrow$ & $2 \mathrm{HO}_{2}+\mathrm{CO}$ \\
\hline
\end{tabular}


TABLE IV. Photolytic Reactions in the Box Model

$\begin{array}{ll}\mathrm{CH}_{3} \mathrm{OOH}+\mathrm{hv} & \rightarrow \mathrm{CH}_{2} \mathrm{O}+\mathrm{HO}_{2}+\mathrm{OH} \\ \mathrm{CH}_{3} \mathrm{O}_{2} \mathrm{NO}_{2}+\mathrm{hv} & \rightarrow \mathrm{CH}_{3} \mathrm{O}_{2}+\mathrm{NO}_{2}\end{array}$

